\title{
Electrochemical and Spectrophotometric Characterization of the Propolis Antioxidants Properties
}

\author{
Anna Masek ${ }^{1, *}$, Ewa Chrzescijanska ${ }^{2}$, Malgorzata Latos ${ }^{1}$, Anna Kosmalska ${ }^{1}$ \\ ${ }^{1}$ Technical University of Lodz, Institute of Polymer and Dye Technology, Faculty of Chemistry, 90- \\ 924 Lodz, ul. Stefanowskiego 12/16, Poland \\ ${ }^{2}$ Technical University of Lodz, Institute of General and Ecological Chemistry, Faculty of Chemistry, \\ 90-924 Lodz, ul. Zeromskiego 116, Poland \\ *E-mail: anna.masek@p.lodz.pl
}

doi: $10.20964 / 2019.02 .66$

Received: 5 October 2018 / Accepted: 27 November 2018 / Published: 5 January 2019

In this work, ethanol extracts of propolis from Europe, before and after 10 years of storage, were prepared and investigated by electrochemical methods, FTIR, and UV-Vis spectrometry assays. A combination of electrochemistry (cyclic and differential pulse voltammetry) and spectrometry allowed for the establishment of chemical correlation between the composition and the activities of bioactive polyphenols. Based on the content of the individual components and their content groups, the antioxidant properties of propolis precursors were characterized. Extracts of propolis before (ExI) and after 10 years (ExII) of storage were irreversibly oxidized in at least two electrode stages. ExII was oxidized more difficultly than ExI, and revealed better antioxidant properties. The antiradical and overall antioxidant potentials of the substances present in the extract of propolis after 10 years of storage, have been demonstrated in this paper. The storage time (10 years) did not significantly alter the properties of propolis, as evidenced by the high potential for free radical scavenging (ABTS, DPPH) and reduction of metal ions. Some of the materials present in propolis have been oxidized, and as confirmed by the FTIR analysis, this facilitates the passage of polyphenols from the propolis into the anhydrous (ethanol or acetonitrile) environment. Thus, propolis, as a rich source of natural phytocompounds, may be used in the prevention of various free radical-related ailments.

Keywords: propolis; antioxidant; electrochemistry; spectroscopy; phytochemistry

\section{FULL TEXT}

(C) 2019 The Authors. Published by ESG (www.electrochemsci.org). This article is an open access article distributed under the terms and conditions of the Creative Commons Attribution license (http://creativecommons.org/licenses/by/4.0/). 